\title{
A Constructivist Approach to Visualise Organisational Agility
}

http://doi.org/10.21272/bel.5(2).96-106.2021

Henning Bundtzen, ORCID: https://orcid.org/0000-0002-0098-8886

PhD Candidate, Organizational Developer, Faculty of Economic Science, Szent István University, Budapest, Hungary

Mark Heckmann, ORCID: https://orcid.org/0000-0002-0736-7417

Dr., Data Scientist/Analyst, DB Station\&Service AG, Germany

Gerriet Hinrichs, ORCID: https://orcid.org/0000-0002-4490-3856

PhD Candidate, Human Resource Manager, Faculty of Economic Science, Szent István University, Budapest, Hungary

\begin{abstract}
The research question we would like to answer with this article is if agile related constructs or personal assessment criteria can be elicited from a personal construct system of employees and leaders by carrying out a repertory grid study in an organisation. The methodology of personal construct psychology was chosen to get an unbiased view of the corporate culture. In a plannable world an organisational structure with a hierarchy of executives and managers following a vertical top-down approach makes sense. A world that is volatile, uncertain, complex, and ambiguous (VUCA) requires a different model to organisational design. Horizontal integration that fosters involvement and empowerment has proven to be an agile response to this new environment. Consequently, agile management methods are a key instrument for an organisation to prepare for future challenges in a competitive industry. But how can an organisation assess its own agile status quo? This research uses personal construct psychology (PCP) to visualize the agility status of an organisation. A range of recent empirical and practical research articles were studied to filter the most relevant practices and critical factors of organisational agility. The findings are compared to a data basis generated by 61 repertory grid interviews carried out in a SME to evaluate whether personal construct theory is a suitable approach to assess the agility status of an organisation. The findings are visualised with a repertory grid software using Generalised Procrustes Analysis (GPA). This methodology creates a 3D visualisation of the agile assessment criteria derived from the interviews. By comparing the spatial distances between construct clusters and elements the researcher and reader able to assess whether an organisation has incorporated agile practices and traits or can further advance to react more agile and flexible to external forces. Repertory grid structured interviews based on PCP generate simultaneously quantitative and qualitative results. As these are compared to the literature-based findings, it reflects a triangulation research approach.
\end{abstract}

Keywords: Agile Organization, VUCA, Corporate Agility, Repertory Grid Analysis, Personal Construct Psychology.

JEL Classification: L20, L22, M14, M21.

Cite as: Bundtzen, H., Heckmann, M., Hinrichs, G. (2021). A Constructivist Approach to Visualise Organisational Agility. Business Ethics and Leadership, 5(2), 96-106. http://doi.org/10.21272/bel.5(2).96-106.2021.

Received: 29 March 2021

Accepted: 13 May 2021

Published: 25 June 2021

Copyright: (C) 2021 by the author. Licensee Sumy State University, Ukraine. This article is an open access article distributed under the terms and conditions of the Creative Commons Attribution (CC BY) license (https://creativecommons.org/licenses/by/4.0/).

\section{Introduction}

Organisational agility can be described as "an organisation's capacity to respond, adapt quickly and thrive in the changing environment" (Holbeche, 2019). Alternative definitions focus on the agile practices as "an umbrella term for a set of management practices - including Scrum, Kanban, and Lean" (Denning, 2016). These two definitions emphasize the different approaches towards an agility concept, focusing on enablers and capabilities or agile management practices (Zitkiene \& Deksnys, 2018). Firstly, however, the factors that induce agile organisational structures and methods must be described (Holbeche, 2019). 
The key to why an organisation should become agile lies in the environmental forces described by VUCA. This concept became more relevant than ever in pandemic-affected 2020. According to Baran and Woznyj (2020) organisations get best through turbulence by guiding through a set of three interrelated actions: identify one's VUCA, define obstacles to agility and implement agility-enhancing practices (Baran \& Woznyj, 2020). One of the main obstacles to agility is the inertia of the status quo. Leaving the comfort zone and routine is not liked by humans as it increases cognitive effort (Nijssen \& Paauwe, 2012). Another barrier lies in the available time and organisational design. These structural or policy obstacles can be referred to as "silos" amongst departments. They prevent cross-functional teamwork and knowledge sharing (Baran \& Woznyj, 2020; Sherehiy et al., 2007). A volatile economic environment with uncertainties and ambiguity does not fit hieratic organisational structures and long-term plans. Organisational agility is the approach to close the disparity between the speed of corporate learning and that of economic change (Appelbaum et al., 2017a).

Hence, what is the exact problem with a VUCA world? It can be a threat to the performance of an organisation if the opportunity in volatility and uncertainty is not seen as a possibility for achieving a competitive advantage but rather a threat. Creativeness in problem-solving and addressing uncertain and unpredictable situations is essential in the context of agility (Ganguly et al., 2009; Giachetti et al., 2003). In addition, learning work tasks, new technologies, or procedures are necessary in a VUCA world (Pulakos et al., 2000; Xing et al., 2020). No plans or set of tools are available that an organisation can implement to address ambiguity or uncertainty in its operating market. Agile practices, a shift into a growth mindset, and a focus on agile requirements will allow organisations to proceed along the agile path and enable a constant closure of the disparity between organisational structure and economic environment (Dweck, 2016; Harraf et al., 2015).

How well and advanced an organisation is regarding the characteristics mentioned above can be evaluated with specific models or questionnaires. These generate either quantitative or qualitative data. A new approach to assess the agile status would be the application of PCP, creating quantitative and qualitative data simultaneously. As this approach was chosen, an entire data set of 782 constructs was generated, clustered semantically into 36 unique clusters. From the total data set generated in this study, 19 out of 36 clusters were associated with agile traits, enablers or practices. These clusters were categorised into the categories error handling, job attitude, leadership and working conditions. By comparing the spatial positions of the centric points of these clusters with elements like "the company today" or "the leadership culture," it is possible to assess the agile status quo of the organisation. Furthermore, determinative poles like "A negative company" and "An ideal company" were integrated, this research highlights the perceived agile associations of employees and leaders. True comparability to other organisations will only be given, if several organisations are analyzed by applying the element set of this study. It was not the scope of this study, as the prime aim is to evaluate in a first step if PCP is a possible approach to analyze organisational agility. Nevertheless, the element "an unpleasant competitor" can give an outlook on how the organisation benchmarks against its competition.

\section{Literature Review}

Agile Practices. Organisations implementing agile practices recount faster innovation processes and better responsiveness to customer needs whilst experiencing a higher employee engagement (Ganguly et al., 2009). These practices originated in software engineering and have integrated into management theory in general (Denning, 2016). It explains why agile and Scrum have become increasingly popular (Denning, 2015). According to Bennet et al. (2014), addressing complexity, on the contrary, requires simplification and an organisational structure that mirrors the environment. It means that the structure, such as branches and processes, must constantly be aligned to the environmental complexity (Kotter, 2012). On the other hand, Ambiguity requires a mindset of experimentation more than any other, as cause-and-effect relationships are not certain. It involves a willingness to take risks and invest resources for innovation (Bennett \& Lemoine, 2014; Crocitto \& Youssef, 2003). Corporate ambidexterity is found as a response to the ambiguous environment; it aims to simultaneously incorporate exploitation and exploration (Harraf et al., 2015). More precisely, exploration is meant to support the organisation's innovation, whilst exploitation ensures the company's survival (Du \& Chen, 2018; Zitkiene \& Deksnys, 2018) without disrupting daily operations and cash flow (Kotter, 2012). The dynamic capability to act flexibly, adapt to new situations quickly and approach new situations proactively is realised as a competitive advantage and tackles economic volatility (Appelbaum et al., 2017a; Baškarada \& Koronios, 2018; Felipe et al., 2016; Zitkiene \& Deksnys, 2018). Scrum embraces timeboxing in combination with an iterative approach to ensure short reaction times in a volatile environment (Nurdiani et al., 2019). Recurring retrospective meetings in Scrum ensure that processes, technical conditions, and teamwork function well, so they do not impede effectiveness.

In the agile or Scrum world, transparency is a key factor. A method to achieve this is the Kanban board which allows all team members to see who is working on which task and how long (Nurdiani et al., 2019). Short, 
daily meetings reinforce this transparent culture and ensure a constant knowledge sharing of team members. Volatility is the main driver for this procedure, and it corresponds to fast-changing circumstances and customer preferences (Harraf et al., 2015). Later agile practices integrate direct contact and interaction with customers combined with continuous environment scanning to ensure that customers focus on the conducted work (Appelbaum et al., 2017b; Crocitto \& Youssef, 2003). This focus is kept through some "lens", which in the Scrum ideology is called "product owner" (Denning, 2015; Rigby, Darrell K., Jeff Sutherland, and Hirotaka Takeuchi, 2016). Getting customers periodically on-site reinforces the attention to customer value (Nurdiani et al., 2019).

Finally, the iterative way, including periodical assessment reviews called product review meetings, highlights customer needs. The emphasis is on the added value for the customer to ensure that customer preferences have not changed. This iterative approach with shorter time frames in project management is under motivational theories, as target achievements are constantly visible. Instead of having an important, timewise far goal, the targets are closer, and likewise, rewards are continuous (Eshlaghy et al., 2010). The agile practice further includes translating customer requirements into user stories to minimize requirement ambiguity (Nurdiani et al., 2019). The user or customer stories are discussed and evaluated in a planning meeting, reinforcing transparency and knowledge sharing. Team members prioritize the task themselves and decide how a task is accomplished. In this manner, self-organising teams facilitate the usage of the entire talent capacity of the team (Nurdiani et al., 2019; Eshlaghy et al., 2010). It usually contradicts typical organisational structures and hierarchy, where management decides how tasks are accomplished and how teams are organised. Eshlaghy et al. (2010) further formulated that agility features progressive manufacturing technology and progressive design technology, which are crucial for rapidly changing environments and preferences.

Agile Enablers and Capabilities. The implementation of agile practices alone does not have a lasting effect on organisational agility and innovation. A cultural change must occur that includes leadership behaviour and change management on different levels to achieve this goal over the long term (Holbeche, 2019; Kotter, 2012). However, many firms struggle to expand agility from a project level or a single department to the entire organisation. One critical change is the primary driver of the firm's activities, where the perspective changes from a shareholder value to a customer value approach (Zitkiene \& Deksnys, 2018). The ideology suggests that long-term sustainable profits and a competitive advantage resulting from fast and continuous customer value-based innovation (Holbeche, 2019). One toehold of Scrum methodology is it ensures constant interaction and focus on customers. As a consequence, the cultural mindset of cooperation must change to evolve towards agility. Customer needs are focused, resulting in more thinking, and acting towards adding value to the product than about the organisation itself (Denning, 2016). In this way of thinking, profit-seeking is a result but not the aim itself (Denning, 2016).

As a first point, the organization needs a strategic commitment to organisational agility supported by all leaders in unity (Xing et al., 2020; Sherehiy et al., 2007). It makes a shift in power compulsory, away from hierarchy and management and towards the marketplace and customer needs (Iivari \& Iivari, 2011). Leaders must implement the above-described agile practices and be ready to transfer control to lower hierarchical levels (Appelbaum et al., 2017a; Crocitto \& Youssef, 2003). Making an organization agile requires replacing hierarchical and bureaucratic practices with cross-functional teams. Often, however, teams are established on an ad-hoc basis and afterward, a project is abandoned again (Denning, 2015). Denning (2015) describes this scenario as flattened corporate hierarchies without removing them entirely. Conflicting goals arise in particular when the hierarchical structure is kept, and the horizontal approach of Scum or agile teams are implemented alongside without full management support.

The contradiction is based on the differing mindsets, values and attitudes of the involved people with missing interpersonal and cultural adaptability (Sherehiy et al., 2007; Pulakos et al., 2000). In other words, empowerment is emphasised, but the substantial authority remains in executive positions instead of being transferred to the team. A holistic conversion requires managers and employees to acknowledge and implement a participative decision-making process (Crocitto \& Youssef, 2003). It presupposes a cooperative leadership style away from a predominant autocratic form of leading. Mindfulness in leadership is one way to cope with the challenges and complexity of the current economic environment, which is more disruptive, distractive and stressful to leaders than ever before. Mindfulness at work means a solution to the leadership challenge to manage oneself, a team, or an entire organisation in a VUCA world (King \& Badham, 2019).

The aim is to respond through self-organization and cross-functional teams quickly and flexibly to customer demands and trends (Ganguly et al., 2009; Shams et al., 2020). The role of leadership changes in that agile surrounding. A crucial part for managers becomes removing impediments to ensure the team can perform 
without distraction. On the other side, workers are required to be tolerant, versatile, and adaptable towards uncertain and new situations in today's environment. However, the measurability of flexibility or versatility is problematic (Pulakos et al., 2000; Giachetti et al., 2003). Preparing for volatility comprises increasing agility and piling unbound resources to enable a fast reaction to the expected change, as volatility describes a change in magnitude or speed (Zitkiene \& Deksnys, 2018; Xing et al., 2020; Shams et al., 2020). Uncertainty, in contrast, needs a different approach, as it is unclear if a change will happen. A response to uncertainty can be information collection, knowledge absorption, or data processing to get a better understanding of how innovation might change the future market (Bennett \& Lemoine, 2014; Felipe et al., 2016).

Leaders, in addition, must ensure profitability whilst rigidly driving innovation, which leads to a recommendation of ambidexterity in leadership (Holbeche, 2019; Rigby, Darrell K., Jeff Sutherland, and Hirotaka Takeuchi, 2016). Leadership plays an essential role in ambidexterity, as it ensures the structural conditions needed, such as maintaining the balance of control and empowerment (Shams et al., 2020). On the other hand, leaders arrange contextual ambidexterity by creating the required atmosphere and CC (Du \& Chen, 2018; Iivari \& Iivari, 2011) that respond to the challenges customers put upon organisations. These include constantly changing preferences (Rigby, Darrell K., Jeff Sutherland, and Hirotaka Takeuchi, 2016), under which organisations must continue being efficient and controlling costs (Felipe et al., 2016). This requires an inherited competency of constant market sensing (Nijssen \& Paauwe, 2012; Zitkiene \& Deksnys, 2018).

Furthermore, the mindset must shift from a top-down structural one towards a cultural focus that centres around networks and behaviour. This culture requires a collaboration of the self-organising and cross-functional teams in direct contact with their customers to put customer value in focus. Other vital cultural features are empowerment, continuous improvement, transparency, knowledge sharing and horizontal communication encouragement (Holbeche, 2019; Eshlaghy et al., 2010). Organizational resilience is required to enable rapid and flexible reactions to ever-changing consumer needs and economic circumstances. The common attitudes of involvement and engagement by leadership are necessary to support an organization's resilience (Sherehiy et al., 2007). It again highlights leaders' role in shifting an organisation from a hierarchical institution to an agile working platform. Constant renewal is required to be combined with the well-being of employees (Baškarada \& Koronios, 2018). Ideally, leaders achieve a shared purpose and common goal in their workforce, which, especially among millennials, leads to a higher commitment and hence performance (Costanza et al., 2012).

Gary Hamel (2014), author of Humanocracy, argued that leaders must shift their entire mindset away from common management practices, which have much to do with control and authority. It, alongside bureaucracy, must make way to agile attitudes, which is the only way to enact real empowerment and utilization of the entire human potential of workers (Hamel, 2014; Crocitto \& Youssef, 2003). Another obstacle in agile transitions is employee resistance caused by greater interpersonal demands and higher degrees of uncertainty and insecurity at the beginning. Stress can be a cause resulting in the opposite effect of the desired resilience. As leaders are put in the same conflict and challenge, they must "walk the talk" as role models of an agile work attitude. Even within the four terms of VUCA, each requires a different response depending on how distinctive they are in the respective industry (Xing et al., 2020). To be prepared to react to a volatile and heterogeneous market, the best response is leveraging the organisation's agility (Bennett \& Lemoine, 2014; Nijssen \& Paauwe, 2012; Shams et al., 2020). In summary, the literature review advocates that the constructs outlined in Table 12 are considered as they relate to the mentality and culture reflecting an agile organisation.

Table 1. Agile Organisational Traits

\begin{tabular}{|c|c|c|c|}
\hline Volatility & Uncertainty & Complexity & Ambiguity \\
\hline Leaving comfort zone & Knowledge sharing & Simple organisation & Experimentation \\
\hline Focus on customer needs & Market sensing & Mirror to environment & Take risks \\
\hline Flexibility & Iterative work & Growth mindset & Ambidexterity \\
\hline Self-organising teams & Transparency & Cooperative leadership & Customer focus \\
\hline Control/authority & Cross-functional teamwork & Shared purpose/common goal & Engagement \\
\hline Unbounded resources & Horizontal communication & Involvement & \\
\hline Continuous improvement & & Empowerment & \\
\hline
\end{tabular}

Source: Compiled by the authors

\section{Methodology and Research Methods}

This qualitative study utilizes an inductive method to explore operational agility in a modern work setting. In a grid analysis, Kelly's (1955) personal construct psychology (PCP) provides a theoretical approach and perspective for developing a detailed data collection within an enterprise as a prerequisite for assessing and 
visualizing the agile status quo of a company. In his philosophy, Kelly (1955) proposed that people, like scientists, are trying to make sense of their universe and their position within it (Cassell et al., 2000). It is accomplished by relating perceptions and objects to one another in various ways (Fromm, 2004). This principle is applied to an organisation that surrounds an entity in the framework of this study. As a result, an originally social hypothesis is used to assess how people feel about the company they work for in agile-related constructs. In this context, according to PCP, people form personal constructs or ideas about themselves, and their organizations based on their life experiences (Fransella et al., 2004). The repertory grid technique based on PCP was chosen to employ a qualitative and quantitatively unbiased tool (Robertson, 2004) to evaluate whether agility-related estimations are inherent naturally in a worker's mindset about an organization. Rather than being a psychometric survey, repertory grid tests are a standardized interview procedure based on PCP (Fromm, 2004). They compare organizational components in this way. A data matrix records the proband's wording to separate these components (Scheer and Catina, 1993). In an idiographic way, these findings reflect the interviewed person's subjective perception of the company they work for (Bourne and Jankowicz, 2018).

A total of 61 repertory grid organized interviews were conducted inside an institution as a basis for this study. The research object is a consumer wholesale corporation with about 500 employees, 21 of whom are in leadership positions. The interviews were collected and analyzed using the rep:grid application. The interviewer can select from a variety of interview settings for this method. The triad oppositional contrast approach was chosen for the underlying research. Probands were faced with three separate components to evoke their structures. In a tetrapolar field, the evaluation of all elements was conducted by the interviewees. The web-based tool produces a three-dimensional visualization after the interview is completed, allowing for consensus validation of the elicited constructs (Lohaus, 1983). As agile management practices include a shift of power from managers to lower hierarchical levels, the interviews were conducted with all managers and 40 staff representing each company's department. The computer-assisted interviews (every 2 hours on average) generated a total of 782 personal constructs. The data set focuses on one cooperation only to ensure that practical applicability is given. If several organisations are taken and their results mixed, this would not correspond to the research aim. A possible further research approach could be to assess several organisations simultaneously and comparing the results. In a first step, it is essential so to analyze whether one organization can be assessed with regards to the agility status by applying personal construct psychology.

The applied repertory grid methodology asks the interviewee to define what they equate with the elements provided to them in their own words (Goffin, 2003). In this way, their view of the organisation around them is shaped by their internal structures or measurements, representing how they assess and judge the components that make up the organization (Kelly, 2002). Specific simple guidelines must be followed when determining the investigating components to ensure comprehensive coverage of the research subjects. One important prerequisite for selecting elements is that they are homogeneous. It means that they are required to belong to the identical group, that they are descriptive of the subject under investigation, and that the elements are unambiguous in their meaning (Easterby-Smith et al., 1996). In addition, a limited number of more heterogeneous elements can result in more diverse and creative constructs which represent the domain of interest (Wright and Lam, 2002). This study used 27 components to describe the organisation, all of which were created to establish structures related to organizational agility.

During this analysis, the elements mentioned above were kept unchanged, allowing for the reconciliation of many personal realities into a precise quantitative data set (Hauser et al., 2011). It is impossible to forecast any derived constructs from the components mentioned above, but the context specifies that topic-related constructs are generated in an inductive manner (Fransella, 2004). As a result, probands did not respond to questions and considerations that they have not previously seen. Since the literature review emphasized the importance of leadership in corporate agility, several elements were selected to elicit experiences and thoughts about leadership. The repertory grid hierarchical interview process consists of three distinct phases: First, the methodology allows interviewees to build their constructs by comparing a triad of three particular elements from the set of 27. "Which way are two of these three elements similar to each other but differ from the third one?" the subjects are questioned when presented with the first triad of elements. Contextual structures are elicited as the components are tied to business ethos and leadership. Such elements as "Efficient process" encourage innovative thoughts to evoke a varied set of qualitatively distinct metaphors that characterize the organizational community. Preferably these are linked to agility-related ideas as this was the domain of interest of the presented case study. Kelly asserted that we analyze and characterize our universe based on construct similarities and distinctions. The architecture of repertory grids allows investigating the bipolarity of personal constructs (Fransella, 2004). 
In the second half of the interview, the interviewees say things that contradict their initial build. In step three, interviewees score all 27 elements in the tetrapolar field based on their generated poles. This procedure was replicated until there were no other structures to evoke (Riemann, 1991). Lohaus (1983) showed that element similarity testing has temporal consistency and is consistent with systems created using alternative analysis methods. Feixas et al. (2002) concluded that the repertory grid methodology as a research method has no flaws in durability and validity. Since it has the same meaning as conventional methodologies, it can be used to assess consistency using formal interviews (Fromm, 2004). The comprehensive data set of 782 personal constructs was analyzed by applying Generalized Procrustes Analysis (GPA) to generate the unique coordinates of each construct and element. GPA enables three-dimensional data matrices to be analyzed and visualized (Mak et al., 2013).

The study shows how the derived structures are clustered and positioned in relation to one another (Grice and Assad, 2009; Gower, 1975). The probability of structures occurring next to each other is represented by mathematical distances between the graded elements and statistical indicators (Senior and Swailes, 2004; Tomic et al., 2015). The aim of interpreting the elicited matrix is to construct clusters with similar meanings (Hauser et al., 2011). Furthermore, the relationship between element position and related structures provides insight into the interviewees' contextual environments. The GPA was conducted in three dimensions to ensure practicability and to promote descriptive qualitative research, with the data plotted in three dimensions.

A shared understanding of the spatial representation shown in this study's 3D graphics is also needed to interpret the findings. The distances between clusters of structures and components and their placement in three-dimensional space are quantitative figures that make a qualitative study of the repertory grid by their interaction (Hauser et al., 2011). If the coordinates of structures and components have a particular slight distance between them, it indicates that they are valued similarly. The two elements, "A negative company" and "The ideal company," provide orientation in this three-dimensional space, as these two elements represent the positive and negative poles for this study. The lengths between these poles (up to 100) reflect how positive or negative a subject is perceived. The unique arrangement of elements and created clusters allows the researcher to review the repertory grid findings mathematically.

Cluster formation: The GPA generates a data matrix that assigns a specific set of coordinates to each construct and element. The program rep:grid was used to create a specific collection of clusters based on construct proximity and all constructs. As a pure mathematical determination, this preview cluster collection must be checked semantically. The functionality was used to build the first series of clusters as a starting point for this study. In a second stage, the constructs clusters were compared to agility-related traits, enablers and practices to see if they were compatible. Both constructs were semantically analyzed and assigned to one of the original or new clusters in a final qualitative approach. It resulted in 36 clusters, for which rep:grip used GPA to determine the centric location of these cluster topics. It enables to assess of which semantic clusters the organization's employees and managers equate with a particular element of the organisation, allowing the researcher to determine the agile status quo of the organisation from the inside. One has to emphasize that it is limited to an internal view, lacking an external assessment by competitors, suppliers, or customers. An extension with evaluation by these stakeholders would further validate the purely internal collected perspectives.

\section{Results}

From the literature, several traits and practices regarding the status quo of an agile organisation were drawn. Table 3 lists the clusters of the underlying repertory grid study referring to these traits. One important part of organisational agility highlighted in the literature review was that leaders and employees must leave their comfort zones. Two contrary construct clusters refer to this trait in the study's figures, namely work-to-rule and stay in the comfort zone. In particular, regarding staying in the comfort zone, the "company today" is rated highly (78\%), work-to-rule as a degree of association of 58\%. As a consequence, the organisation must focus on developing this part of organisational culture to progress towards a higher agility degree. Advancing the proactivity of employees, though requires a distinct set of cultural values and leadership prerequisites. These are valuable starting points to evolve the organisation towards corporate agility. 
Table 3. Clusters Relevant for Analysing Organisational Agility

\begin{tabular}{|c|c|c|c|c|c|c|c|c|c|}
\hline & \multirow[b]{2}{*}{ Topic-related clusters } & \multicolumn{2}{|c|}{ Constructs } & \multicolumn{6}{|c|}{ Degree of association } \\
\hline & & $N$ & in $\%$ & $\begin{array}{c}\text { The } \\
\text { company } \\
\text { today }\end{array}$ & \begin{tabular}{|c|} 
An \\
unpleasant \\
competitor
\end{tabular} & $\begin{array}{l}\text { The } \\
\text { market in } \\
\text { the future }\end{array}$ & $\begin{array}{c}\text { A } \\
\text { negative } \\
\text { company }\end{array}$ & $\begin{array}{c}\text { Leader- } \\
\text { ship } \\
\text { culture }\end{array}$ & $\begin{array}{c}\text { Employee } \\
\text { culture }\end{array}$ \\
\hline \multirow{4}{*}{ 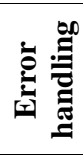 } & Error prevention & 23 & $2.9 \%$ & 0.701 & 0.687 & 0.402 & 0.857 & 0.614 & 0.708 \\
\hline & Organisational silence & 15 & $1.9 \%$ & 0.704 & 0.651 & 0.337 & 0.900 & 0.601 & 0.703 \\
\hline & Honest, critical feedback & 15 & $1.9 \%$ & 0.424 & 0.476 & 0.949 & 0.310 & 0.489 & 0.430 \\
\hline & Open error culture & 21 & $2.7 \%$ & 0.498 & 0.516 & 0.873 & 0.390 & 0.551 & 0.516 \\
\hline \multirow{4}{*}{ 율 } & Work-to-rule & 28 & $3.6 \%$ & 0.579 & 0.733 & 0.382 & 0.841 & 0.499 & 0.595 \\
\hline & Past customer needs & 12 & $3.6 \%$ & 0.724 & 0.644 & 0.459 & 0.773 & 0.651 & 0.752 \\
\hline & Focus on customer needs & 29 & $3.6 \%$ & 0.647 & 0.546 & 0.745 & 0.487 & 0.697 & 0.660 \\
\hline & Stay in the comfort zone & 18 & $2.3 \%$ & 0.783 & 0.583 & 0.347 & 0.817 & 0.672 & 0.785 \\
\hline \multirow{4}{*}{ 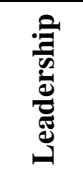 } & Controlling supervisors & 14 & $1.8 \%$ & 0.862 & 0.586 & 0.465 & 0.677 & 0.811 & 0.814 \\
\hline & Clear \& distributed responsibilities & 20 & $2.6 \%$ & 0.495 & 0.507 & 0.896 & 0.371 & 0.556 & 0.506 \\
\hline & Involvement is missing & 21 & $2.7 \%$ & 0.664 & 0.735 & 0.384 & 0.886 & 0.580 & 0.658 \\
\hline & Inclusion and involvement & 15 & $1.9 \%$ & 0.503 & 0.367 & 0.817 & 0.290 & 0.589 & 0.522 \\
\hline \multirow{7}{*}{ 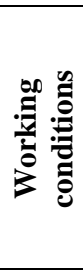 } & Wasteful processes & 31 & $4.0 \%$ & 0.661 & 0.675 & 0.344 & 0.913 & 0.564 & 0.668 \\
\hline & Digitisation/IT capacity & 11 & $4.0 \%$ & 0.495 & 0.551 & 0.871 & 0.400 & 0.547 & 0.503 \\
\hline & Agile working attitude & 23 & $2.9 \%$ & 0.532 & 0.533 & 0.858 & 0.407 & 0.589 & 0.540 \\
\hline & Efficient working conditions & 32 & $4.1 \%$ & 0.511 & 0.474 & 0.862 & 0.345 & 0.588 & 0.509 \\
\hline & Sluggishness in change & 19 & $2.4 \%$ & 0.709 & 0.631 & 0.330 & 0.890 & 0.603 & 0.712 \\
\hline & Continuous optimisation & 21 & $2.7 \%$ & 0.447 & 0.495 & 0.923 & 0.343 & 0.504 & 0.461 \\
\hline & Innovative work environment & 13 & $1.7 \%$ & 0.544 & 0.512 & 0.849 & 0.393 & 0.611 & 0.547 \\
\hline
\end{tabular}

Source: Compiled by the authors

With regard to market sensing capabilities, the two clusters past customer needs and focus on customer needs represent the bipolarity of constructs usually generated by RGIs. Today, the company rates higher on past customer needs ( $72 \%$, compared to $65 \%$ ). Interestingly the element "an unpleasant competitor" (which had to be a specific competitor) ranks even worse on customer need focus, although lower on past customer needs. It can be derived from this case study that this part of organisational traits is generated by RGIs, allowing an assessment of the organisation. More focus on the customer is required to improve the ability to deal with ambiguous customer demands. It includes the mentality in the same way as organizational structure to ensure customer-centricity. As another example, the organisation's approach towards errors has an impact on agility, which does not have the focus it may have.

Figure 1 visualizes the employee's and leader's perceptions of the two error-related clusters. Error prevention, which aims to minimize errors and may lead to suppression of errors, is highly correlated to "a negative company" (86\%). In contrast, an open error culture strongly correlates with an "ideal company" (85\%) and is strongly associated with the cluster's continuous optimization and agile working attitude. In the literature on organisational agility, not much attention is given to error handling. The high degree of association in the underlying data set suggests though that there is a solid interlinkage to achieve continuous improvement of processes and products. In conclusion, an open error culture, where it is recognized that errors happen and that a broader circle of the workforce can learn from mistakes made, is in turn associated with an ideal organisation and supports organisational agility. 


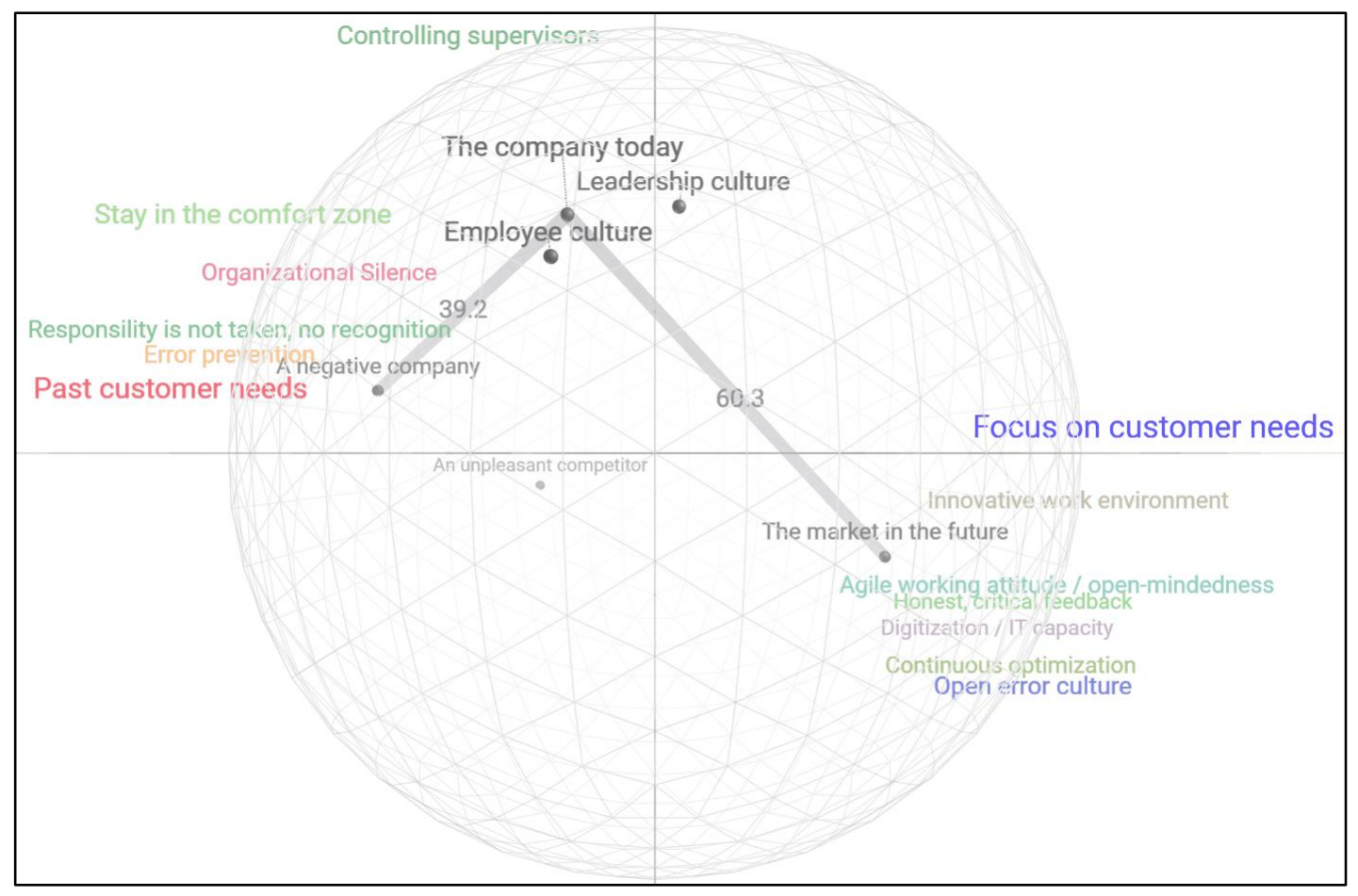

Figure 1. GPA Visualisation of Elements and Clusters Related to Corporate Agility

Source: Compiled by the authors

In addition, the dataset suggests that honest, critical feedback is highlighted as part of the company culture. It strongly correlates with agile working attitudes. Holocracy and Scrum underline this factor with continuous retrospective meetings or a system that ensures constant feedback from any hierarchical level. In this data set honest, critical feedback is closely associated with the requirements for "the market in the future" $(95 \%)$, while the assessment of "the company today" (42\%) highlights that improvement with regards to feedback behaviour can in return support the agility status. The cluster organisational silence, which represents the absence of upward-directed feedback, substantiates this conclusion with a relatively high degree of association (70\%) with "the company today".

The bipolarity of the two construct clusters innovative work environment and sluggishness in change is reflected in the degree of association with "the market in the future". While an innovative work environment is discerned as necessary for the market environment (85\%), the cluster sluggishness in change is positioned far from this element (33\%). Instead, this cluster is highly associated with "a negative company" (89\%), indicating that employees and leaders acknowledge the importance of continuous change. Regarding assessing the company in this exemplary case study, the "leadership culture" $(60 \%)$ and the "employee culture" (71\%) both show some degree of association with sluggishness in change. Again, a toehold to advance agility which requires a change in the employee's mentality. To enable the sensing of market activities and trends, literature on corporate agility advocates digitization and the establishment of respective IT capacities. The aim is an efficient analysis and processing of data. Especially "the market in the future" reflects this insight from the literature review as it is located close to the constructs summarized with digitization/IT capacity (87\%). The assessment of the studied organisation reveals that it has potential for improvement in this criterion for an agile organisation.

Finally, the construct clusters related to inclusion and involvement together with the contrary cluster involvement is missing is analyzed to assess the agile corporate status. "The company today" is rated better with regards to inclusion and involvement (50\%) than "an unpleasant competitor" (37\%), which is reinforced by the lower degree of association for involvement is missing (66\% compared to 74\%). Again, this reflects a possibility to improve, but it can be concluded that the organisation rates better than its competition. Clear and distributed responsibilities are semantically closely related to involvement. The company is on the same level with the competition (both 50\%). The rating shows, though, that handing responsibility over to employees while involving them in decisions is another toehold identified through this study. 


\section{Conclusions}

RGIs based on PCP represent a suitable way to investigate the agile status quo of an organisation. The study shows that it is possible to create agility-related clusters from the entire data set. The degree of association of the distinct clusters enables assessing the agility practices and enablers identified through the previous literature review. There is no RGI study specifically targeted to corporate agility in scientific literature, which indicates that this study represents a new approach to investigate organisational behaviour. The compiled threedimensional plot visualized in Figure 1 allows the researcher and reader furthermore an easily understandable possibility to interpret the results. That way, this investigative methodology can even be applied practically to allow organisations an unbiased way to assess its agility status.

When measuring or visualizing the agile status quo of an organization, the internal properties of the agile systems are often evaluated, whilst reference to the economic environment match is not integrated (Giachetti et al., 2003). It means that there is no alignment between the market requirements for agility, which differ to a great extent between different markets, and the company's agility practices. The same limitation holds for the RGI approach of this research, as it investigates the agility status of an organisation from the inside. It can be argued that the enquired employees and leaders consider the environmental requirements whilst ranking the elements, but this is not ensured by the chosen method. In consequence, this study advocates further research to escalate the scientific research to an external view. It would require a different set of elements, however, which limits comparability to the internal findings. In addition, an inquiry with the same set of elements in other organisations can be another path for future research identified by this study. Comparing the results specifically to the degree of association for the construct clusters elicited can produce exciting insights of how the different agility-related factors influence each other. For example, if further investigated companies show the same closeness of the clusters clear and distributed responsibilities with inclusion and involvement, it can be concluded that these reinforce themselves.

In summary, several starting points to escalate corporate agility were identified for the investigated company. Thus, it can be concluded that RGI is a scientifically and practically suitable methodology for analyzing corporate agility. A questionnaire or interview-based inquiry of employees targeted to agility bears the risk that subjects assess agile factors they would usually not refer to. Even socially desirable answers may be the result as agility is an in-vogue topic in organisational research. The RGIs of this study indicate that agility related thoughts are inherent in the interviewed subjects' perception of the world and organisation around them.

Author Contributions: Conceptualization: Henning Bundtzen and Mark Heckmann; methodology: Henning Bundtzen; software: Henning Bundtzen and Mark Heckmann; validation: Gerriet Hinrichs, Mark Heckmann and Henning Bundtzen; formal analysis: Henning Bundtzen; investigation: Henning Bundtzen; resources: Henning Bundtzen, Mark Heckmann and Gerriet Hinrichs; data curation: Mark Heckmann; writing-original draft preparation: Henning Bundtzen and Gerriet Hinrichs; writing-review and editing: Henning Bundtzen, Gerriet Hinrichs and Mark Heckmann; visualization: Henning Bundtzen; supervision: Mark Heckmann; project administration: Henning Bundtzen; funding acquisition, n/a.

Funding. There is no funding for this research.

\section{References}

1. Appelbaum, Steven H., Calla, R., Desautels, D., Hasan, L. (2017). The challenges of organizational agility (part 1). Industrial and Commercial Training, 49(1), 6-14. [Google Scholar] [CrossRef]

2. Baran, B.E., Woznyj, H.M. (2020). Managing VUCA: The human dynamics of agility. Organizational Dynamics, 50(2), 100787. [Google Scholar] [CrossRef]

3. Baškarada, S., Koronios, A. (2018). The $5 \mathrm{~S}$ organizational agility framework: a dynamic capabilities perspective. IJOA, 26(2), 331-342. [Google Scholar] [CrossRef]

4. Bennett, N., Lemoine, G.J. (2014). What a difference a word makes: Understanding threats to performance in a VUCA world. Business Horizons, 57(3), 311-317. [Google Scholar] [CrossRef]

5. Bourne, D., Jankowicz, D.A. (2018). The Repertory Grid Technique. In: Malgorzata Ciesielska und Dariusz Jemielniak (Eds.), Qualitative Methodologies in Organization Studies, 6, 127-149. Springer International Publishing. [CrossRef]

6. Cassell, C., Close, P., Duberley, J., Johnson, P. (2000). Surfacing embedded assumptions: Using repertory grid methodology to facilitate organizational change. European Journal of Work and Organizational Psychology, 9(4), 561-573. [Google Scholar] [CrossRef] 
7. Costanza, D.P., Badger, J.M., Fraser, R.L., Severt, J.B., Gade, P.A. (2012). Generational Differences in Work-Related Attitudes: A Meta-analysis. Journal of business and psychology, 27(4), 375-394. [Google Scholar] [CrossRef]

8. Crocitto, M., Youssef, M. (2003). The human side of organizational agility. Industr Mngmnt \& Data Systems, 103(6), 388-397. [Google Scholar] [CrossRef]

9. Denning, S. (2015). Agile: it's time to put it to use to manage business complexity. Strategy \& Leadership, 43(5), 10-17. [Google Scholar] [CrossRef]

10.Denning, S. (2016). How to make the whole organization "Agile". Strategy \& Leadership, 44(4), 10-17. [Google Scholar] [CrossRef]

11.Du, J., Chen, Z. (2018). Applying Organizational Ambidexterity in strategic management under a "VUCA" environment: Evidence from high tech companies in China. International Journal of Innovation Studies, 2(1), 42-52. [Google Scholar] [CrossRef]

12.Easterby-Smith, M., Thorpe, R., Holman, D. (1996). Using repertory grids in management. Jnl Euro Industrial Training, 20(3), 3-30. [Google Scholar] [CrossRef]

13.Eshlaghy, A.T., Mashayekhi, Ali N., Rajabzadeh, A., Razavian, M.M. (2010). Applying path analysis method in defining effective factors in organisation agility. International Journal of Production Research, 48(6), 1765-1786. [Google Scholar] [CrossRef]

14.Feixas, G., Geldschläger, H., Neimeyer, R.A. (2002). Content analysis of personal constructs. Journal of Constructivist Psychology, 15(1), 1-19. [Google Scholar] [CrossRef]

15.Felipe, C.M., Roldán, J.L., Leal-Rodríguez, A.L. (2016). An explanatory and predictive model for organizational agility. Journal of Business Research, 69(10), 4624-4631. [Google Scholar] [CrossRef]

16.Fransella, F., Bell, R., Bannister, D. (2004). A manual for repertory grid technique. 2 ed. Chichester: Wiley. Available at: [Link]

17.Fromm, M. (2004). Introduction to the Repertory Grid Interview. Waxmann Pub. Available at: [Link]

18.Ganguly, A., Nilchiani, R., Farr, J.V. (2009). Evaluating agility in corporate enterprises. International Journal of Production Economics, 118(2), 410-423. [Google Scholar] [CrossRef]

19.Giachetti, R.E., Martinez, L.D., Sáenz, O.A., Chen, Chin-Sheng (2003). Analysis of the structural measures of flexibility and agility using a measurement theoretical framework. International Journal of Production Economics, 86(1), 47-62. [Google Scholar] [CrossRef]

20.Goffin, K. (2003). Repertory Grid Technique. In: David Partington (Eds.), Essential skills for management research. Reprinted (pp. 199-225). London: SAGE. [CrossRef]

21.Gower, J. (1975). Generalized Procrustes analysis. Psychometrika, 45(1), 3-24. [Google Scholar]

22.Grice, J.W., Assad, K.K. (2009). Generalized Procrustes Analysis: A Tool for Exploring Aggregates and Persons. AMR, 13(1), 93. [Google Scholar] [CrossRef]

23.Hamel, G. (2014). Bureaucracy Must Die. Harvard Business Review. Available at: [Link]

24.Hauser, M., Jonas, K., Riemann, R. (2011). Measuring salient food attitudes and food-related values. An elaborated, conflicting and interdependent system. Appetite, 57(2), 329-338. [Google Scholar] [CrossRef]

25.Holbeche, L.S. (2019). Shifts in Organizational Culture When Implementing Agility. Journal of Creating Value, 5(2), 124-138. [Google Scholar] [CrossRef]

26.Iivari, J., Iivari, N. (2011). The relationship between organizational culture and the deployment of agile methods. Information and Software Technology, 53(5), 509-520. [Google Scholar] [CrossRef]

27.Kelly, G. (2002). The Psychology of Personal Constructs. Routledge. 810 p. [Google Scholar]

28.Kelly, G.A. (1955). The Psychology of Personal Constructs. Norton, New York. Available at: [Link]

29.King, E., Badham, R. (2019). Leadership in uncertainty. Organizational Dynamics, 48(4), 100674. [Google Scholar] [CrossRef]

30.Kotter, J.P. (2012). Accelerate! Harvard business review, 90(11). [Google Scholar]

31.Lohaus, A. (1983). Möglichkeiten individuumzentrierter Datenerhebung [Possibilities of individualcentered data collection]. Arbeiten zur sozialwissenschaftlichen Psychologie, 12. Münster (Westfalen), Univ., Diss. Münster: Aschendorff. Available at: [Link]

32.Mak, A.H.N., Lumbers, M., Eves, A., Chang, R.C.Y. (2013). An application of the repertory grid method and generalised procrustes analysis to investigate the motivational factors of tourist food consumption. International Journal of Hospitality Management, 35, 327-338. [Google Scholar] [CrossRef]

33.Nijssen, M., Paauwe, J. (2012). HRM in turbulent times: how to achieve organizational agility? The International Journal of Human Resource Management, 23(16), 3315-3335. [Google Scholar] [CrossRef]

34.Nurdiani, I., Börstler, J., Fricker, S., Petersen, K., Chatzipetrou, P. (2019). Understanding the order of agile practice introduction: Comparing agile maturity models and practitioners' experience. Journal of Systems and Software, 156, 1-20. [Google Scholar] [CrossRef] 
35.Pulakos, E.D., Arad, S., Donovan, M.A., Plamondon, K.E. (2000). Adaptability in the workplace: development of a taxonomy of adaptive performance. Journal of Applied Psychology, 85(4), 612-624. [Google Scholar] [CrossRef]

36.Riemann, R. (1991). Repertory Grid Technik. Handanweisung, Auswertungsprogramm, Materialien. Göttingen: Hogrefe. Available at: [Link]

37.Rigby, D.K., Sutherland, J., Takeuchi, H. (2016). Embracing Agile. How to Master the Process That's Transforming Management. Harvard business review, 94(5), 40-50. Available at: [Link]

38.Robertson, A. (2004). Making Sense of the 'Group Mind'. In: Fay Fransella (Eds.), International handbook of personal construct psychology (pp. 339-348). Chichester u.a: Wiley. [CrossRef]

39.Scheer, Jörn W., Catina, A. (Ed.) (1993). Einführung in die Repertory Grid-Technik [Introduction to Repertory Grid Technique], Vol. 2. Clinical Research and practice. 1st ed. Bern, Göttingen, Toronto, Seattle: Huber. Available at: [Link]

40.Senior, B., Swailes, S. (2004). The dimensions of management team performance: a repertory grid study. Int J Productivity \& Perf Mgmt, 53(4), 317-333. [Google Scholar] [CrossRef]

41.Shams, R., Vrontis, D., Belyaeva, Z., Ferraris, A., Czinkota, M.R. (2020). Strategic agility in international business: A conceptual framework for "agile" multinationals. Journal of International Management, 27(1), 100737. [Google Scholar] [CrossRef]

42.Sherehiy, B., Karwowski, W., Layer, J.K. (2007). A review of enterprise agility: Concepts, frameworks, and attributes. International Journal of Industrial Ergonomics, 37(5), 445-460. [Google Scholar] [CrossRef]

43.Tomic, O., Berget, I., Næs, T. (2015). A comparison of generalised procrustes analysis and multiple factor analysis for projective mapping data. Food Quality and Preference, 43, 34-46. [Google Scholar] [CrossRef]

44.Wright, R.P., Lam, S.S.K. (2002). Comparing apples with apples: the importance of element wording in grid applications. Journal of Constructivist Psychology, 15(2), 109-119. [Google Scholar] [CrossRef]

45.Xing, Y., Liu, Y., Boojihawon, Dev K., Tarba, S. (2020). Entrepreneurial team and strategic agility: A conceptual framework and research agenda. Human Resource Management Review, 30(1), 100696. [Google Scholar] [CrossRef]

46.Zitkiene, R., Deksnys, M. (2018). Organizational Agility Conceptual Model. Montenegrin Journal of Economics, 14(2), 115-129. [Google Scholar] [CrossRef] 